\title{
Vegetation Monitoring in Shendong Mining Area by Remote Sensing
}

\author{
Ying Liu and Hui Yue \\ College of Geomatics, Xi'an University of Science and Technology, Xi'an \\ 710054 , \\ Shaanxi, China \\ liuying712100@163.com,yue_hui@live.com
}

\begin{abstract}
Using 2000-2011 MODIS and 1998-2008 SPOT-4/5 satellites NDVI data, with maximum value composites (MVCs) method and linear regression analysis, the dynamic vegetation monitoring change in 1999-2011 of the vegetation coverage in Shendong coal mining area was analyzed. It is revealed that the NDVI in Shendong increases integrally, and the land vegetation coverage in most of the mining area is improved. The vegetation coverage overall showed an upward trend in using simple linear regression analysis, NDVI from MODIS and SPOT data was analyzed both inter-annual and intra-annual change. The spatial pattern of using NDVI calculated that the increase rate of NDVI average of SPOT and MODIS was 9.90\%/10a. Temperature, air pressure, rainfall, solar radiation and other meteorological indicators have similar phenological seasonal variations with vegetation coverage. Moreover, NDVI has an obvious correlation with meteorological factors, such as temperature, rainfall, air pressure.
\end{abstract}

Keywords: Vegetation Monitoring, NDVI, Shendong mining area, environment remote sensing

\section{Introduction}

Vegetation is one of the most important land environmental variables that integrates of atmosphere, soil and water. It plays a critical role in adjusting the composition of the atmosphere, soil and water conservation and keep the balance of climate, etc. Abundant energy and mineral resources are found in the Northwest China where ecological environment is very fragile [1]. Recent years, a series of environmental problems like groundwater level lowering, surface runoff reduced, water pollution and surface subsidence were caused by underground mining, open pit mining and underground mining subsidence, which make the fragile ecological environment further deterioration [2-4]. The change of vegetation is one of the main indicators to reveal the evolution of natural environment in arid and semi-arid mining area. Remote sensing technology can provide land surface parameters, such as normalized difference vegetation index (NDVI), land surface temperature (Ts) and albedo [5-7]. The normalized difference vegetation index is widely used to study land surface process, can provide significant information on land surface vegetation and soil moisture conditions [8].

In recent years, there are so many research on both domestic and abroad which used satellite data NDVI from MODIS and SPOT-4/5 of French for environmental monitoring and vegetation change, but less data is used to monitor the variation in the mining area of vegetation [9-11].Therefore, the spatial and temporal distributions of vegetation characteristics is important in understanding how underground mining and human activities affect the environment in the arid and semi-arid mining area [12-14]. Estimation 
of vegetation properties with remotely sensed imagery has been quite successful. In this paper, based on the characteristics of coal mine environment and vegetation variation and natural conditions in arid and semi-arid of Shendong mining area, use 2000-2011 MODIS and 1998-2008 SPOT-4/5 satellites NDVI data, with maximum value composites (MVCs) method and linear regression analysis revealed that the basic law of Shendong vegetation cover change over the past 14 years, some qualitative and quantitative results are obtained.

\section{Study Area and Data}

Shendong mining area (Figure 1) is located in southeast of the Ordos Plateau, northern edge of the Loess Plateau in northern Shaanxi and the South-East edge of $\mathrm{Mu}$ Us Desert, centered at $\left(110^{\circ} 18^{\prime} 30^{\prime \prime} \mathrm{E}, 39^{\circ} 11^{\prime} 30^{\prime \prime} \mathrm{N}\right)$. This mining area is one of the major coal production bases in China, belonging to the arid and semi-arid desert mine area. The ecological environment of Shendong mining area is fragile and the climate is characterized by less precipitation, uneven seasonal distribution, strong evaporation, and scarcity in surface water resources. Soil moisture is the leading factor of vegetation growth and recovery in this area.

The main remote sensed data are as follows:

(1) MODIS time series products NDVI and EVI with $1 \mathrm{~km}$ resolution between 2000-2011

(2) SPOT-VGT time series data with1 km resolution between 1998-2011

(3) Field investigation data

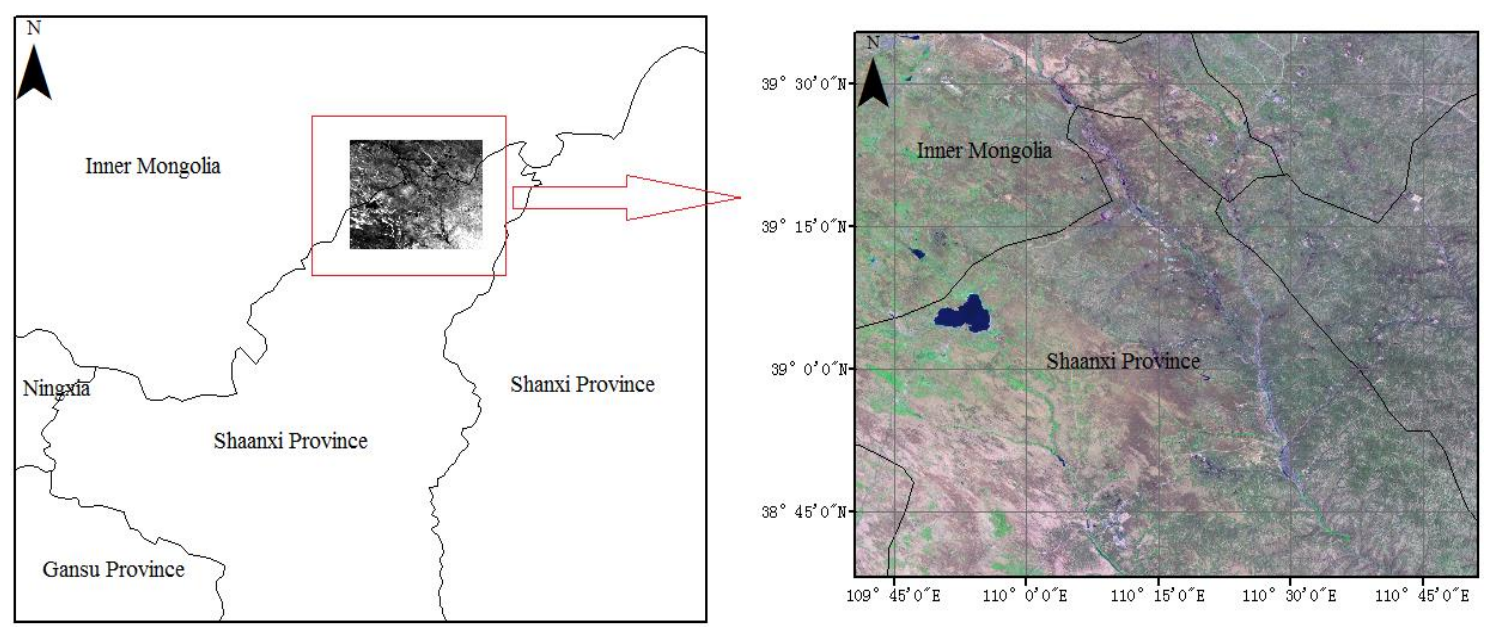

Figure 1. A Map of the Study Area

\section{Methods and Results}

\subsection{Methods}

An NDVI/EVI time series of study area for growing seasons from 2000 to 2011 was produced by assembling MODIS products and SPOT-VGT images. This was accomplished by maximum value composites (MVCs) method which is the most common form of NDVI compositing used to produce NDVI time-series data sets with minimal effects from clouds and atmospheric scattering [15]. The greenness rate of change (GRC) is defined as the slope of the least-squares line fitting the interannual variability of 
seasonally integrated normalized difference vegetation index (SINDVI) values over some time period (e.g. decade) [16].The equation is:

$$
\text { Slope }=\frac{n \times \sum_{i=1}^{n}\left(i \times M_{N D V I, i}\right)-\sum_{i=1}^{n} i \sum_{i=1}^{n} M_{N D V I, i}}{n \times \sum_{i=1}^{n} i^{2}-\left(\sum_{i=1}^{n} i\right)^{2}}
$$

where $\mathrm{i}$ is the number of years between $1-14, M_{N D V I, i}$ is the maximum NDVI value which the number is $\mathrm{i}$.

\subsection{Results}

3.2.1 The Vegetation Change in Study Area: The mean NDVI of every year was obtained which showed that vegetation cover was improved from 1998 to 2011(Figure 2). From 1998 to 2011, the maximize NDVI which obtained from SPOT and MODIS of normal value of accumulated year in Shendong mining area were 0.3608 and 0.3453 respectively, we can see that SPOT-NDVI was higher than MODIS-NDVI in average of many years.

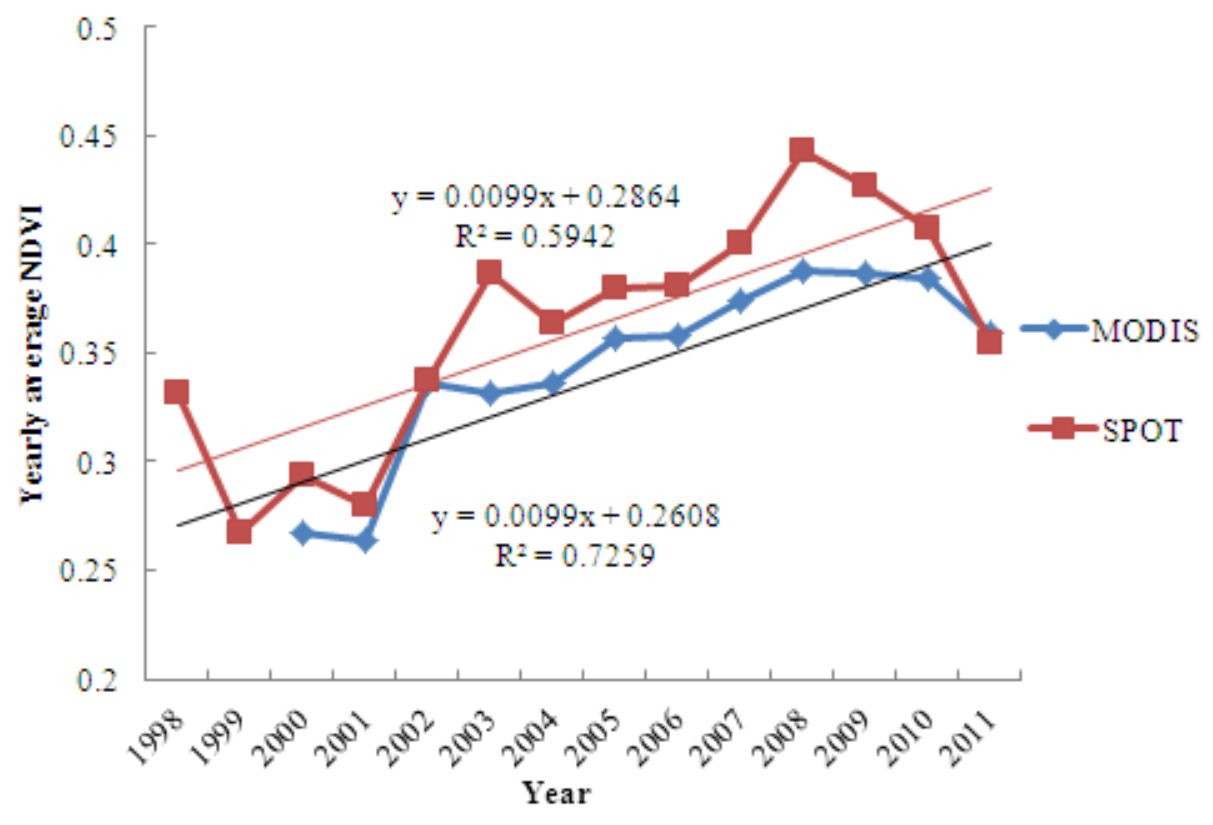

Figure 2 .Yearly Evolution of SPOT/MODIS NDVI

Figure 2 shows that the general curve trends of both SPOT and MODIS average NDVI variation are very similar, the annual maximum NDVI in 1998-2011 is on the rise, and annual maximum NDVI values of SPOT in each year are greater than the average annual maximum of MODIS, which indicated that vegetation of mining area increased in general, the increase rate of NDVI average of SPOT and MODIS was 9.90\%/10a, vegetation coverage has increased faster in 1998-2011.

The figure 3 shows that maximum monthly NDVI within the year of Shendong mining area varying curve acted as a single peak value wave, and at the different time maximize monthly NDVI curves are similar, but the amplitudes are different, and the peak value of maximum monthly NDVI of SPOT were mostly higher than MODIS. 


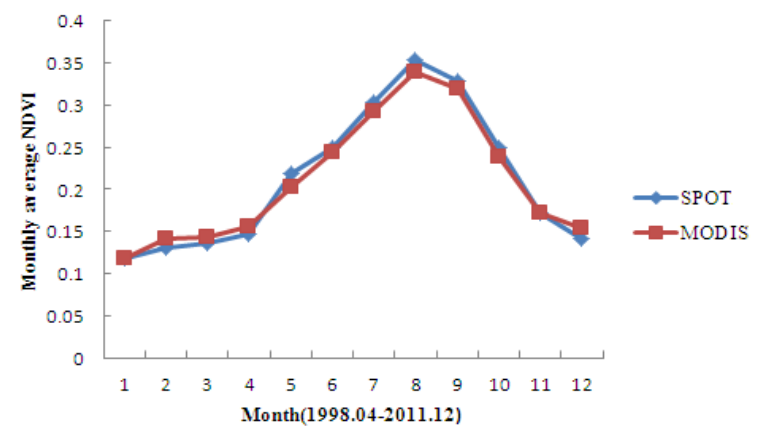

(a)

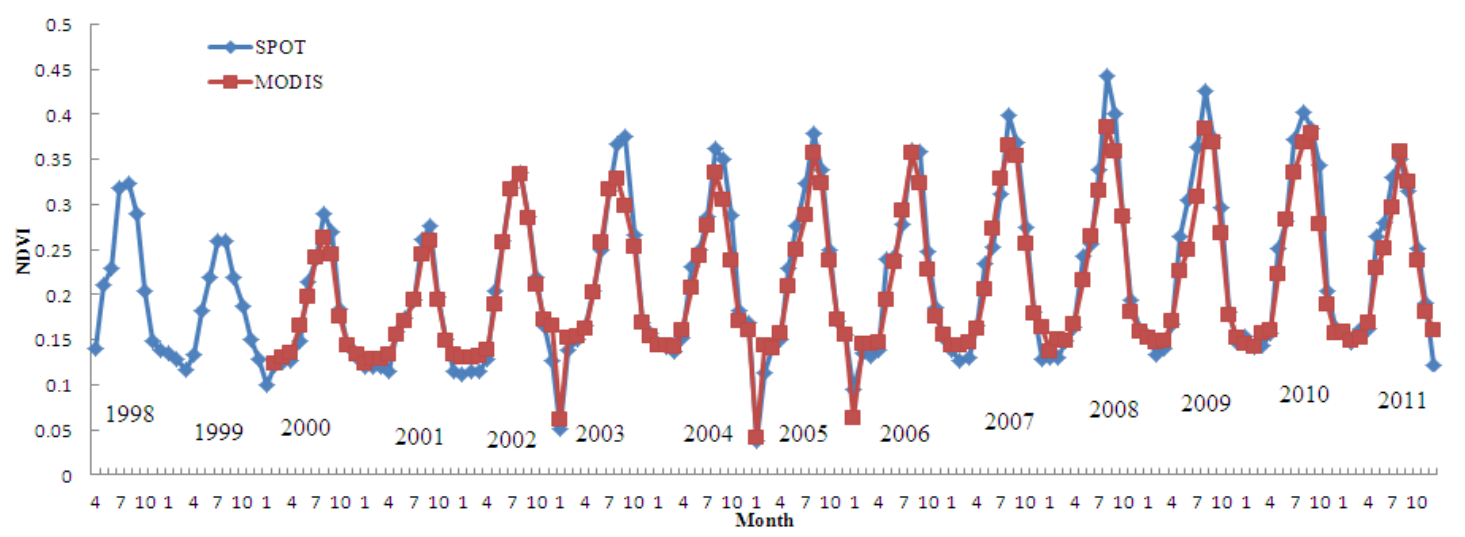

(b)

\section{Figure 3. Yearly (a) and Monthly (b) Evolution of SPOT/MODIS NDVI in Study Area from 1998 to 2011}

Since 1998, the peak value of maximum monthly NDVI began to drop, to 2001, has maintained at a lower level, but after 2002, the maximum average monthly NDVI curve peak had the obvious improvement. From maximum monthly NDVI time-series variation trend, vegetation of Shendong mining area appeared phenological cycle obviously in 14 years. NDVI began to increase in April each year, at the peak value in late July and August, then NDVI gradually decreases, and in the same year in December or the next year January at the valley value. This is mainly influenced by climate characteristics, the temperature of Shendong mining area gradually increased starting from April, rain gradually increased, and it's the most suitable time for vegetation growth and development; from October to the next march vegetation in the withered and yellow phase, coverage was low.With the mining characteristics of air temperature, precipitation and other meteorological factors change, reflects the vegetation growing condition changing with temperature, rainfall and other meteorological factors and complex failure withered phonological rhythm.

From the perspective of inter-annual variation of vegetation, there was a significant decline of NDVI from 1998 to 1999 in the study area, which was similar in 2000 to 2001. Since 2002, the average annual maximize NDVI of Shendong mining area can be roughly divided into three stages: (1) there was a noticeably improved from 2001 to 2003, annual average NDVI was increased by about $38.25 \%$; (2) the annual average NDVI showed a slower growth trend after 2003; (3) annual average NDVI showed a declining trend after 2009.

In most of shendong mining area, the vegetation cover was well improved in the past 12 years and the vegetation, lying in the both sides of Wulan Mulun River and the western and northwestern of the mining area, was degraded (Figure 4a). On the whole, the area of the improved is larger than the degradation of vegetation. The area of 
improved accounts for $76.82 \%$ of the total mining area while the area of degraded accounts for $15.43 \%$ ( Figure $4 b$ ).
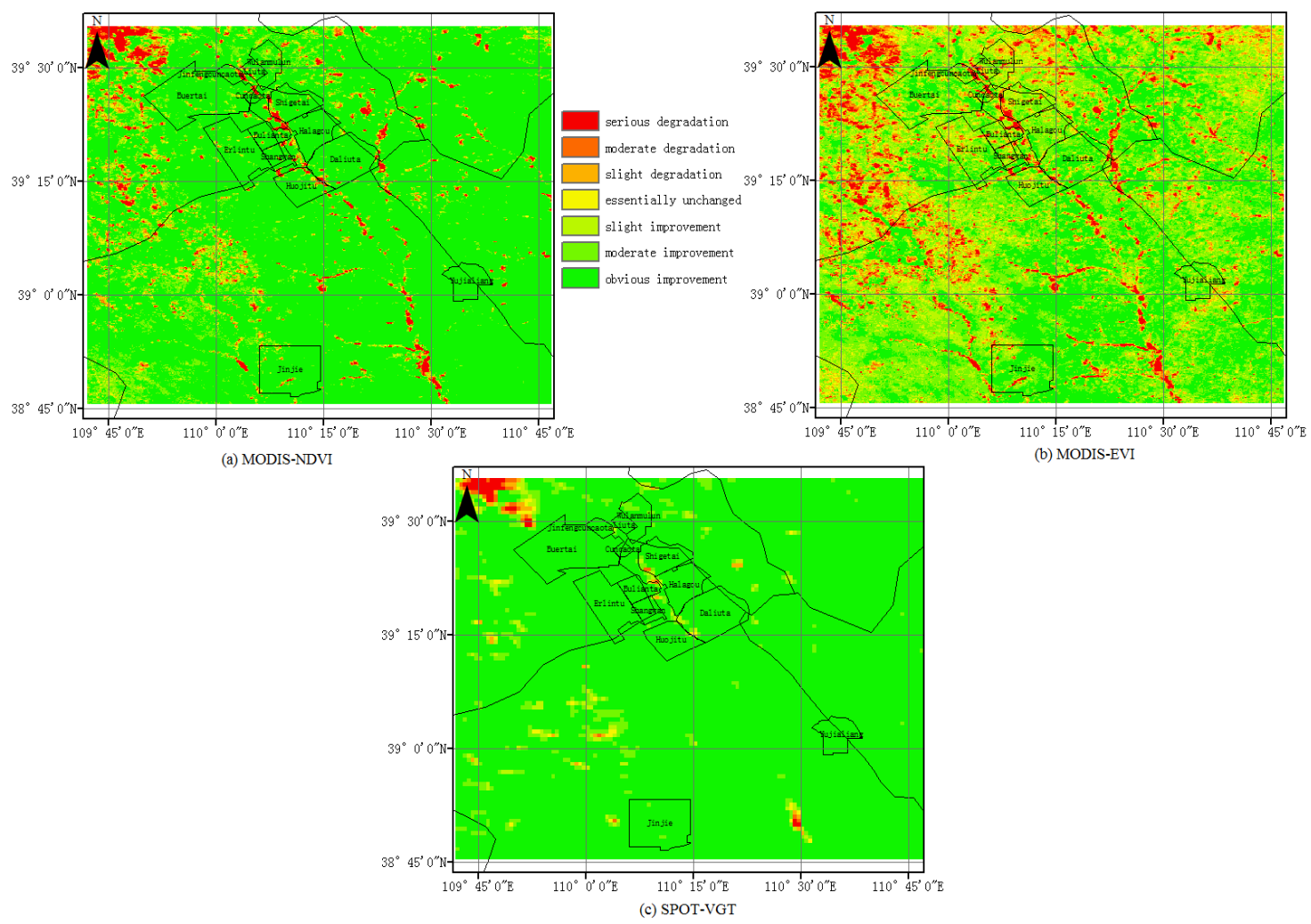

Figure 4. Spatial Distribution of SPOT/MODIS NDVI/EVI Changes in Study Area from 1998 to 2011

3.2.2 Correlation Analysis between Vegetation and Climate Factors: We collected meteorological data from west mountain weather stations of Daliuta and Shenmu weather stations between 2000-2011 in Shendong mining area, and selected 7 commonly used meteorological factors: monthly average rainfall, monthly average relative humidity, monthly average temperature, monthly average evaporation, monthly average air pressure, monthly average wind speed and monthly average solar radiation, combined with annual output of coal, analyzed correlation between these indicators and vegetation.

Table 1 showed that the correlation matrix between NDVI and climatic factors of SPOT/MODIS, maximize monthly $1 \mathrm{~km}$ resolution SPOT-NDVI and MODIS-NDVI have high relevance related coefficient which reached 0.9810; monthly maximize SPOT-NDVI and MODIS-NDVI and monthly temperature significantly related, related coefficient respectively reached has 0.7350 and 0.7420 ; second is monthly rainfall, respectively for 0.6970 and 0.6850 ; then is sun radiation strength, respectively for 0.5800 and 0.5520 ; and monthly pressure has negative related relationship, related coefficient respectively for0.5100 and-0.4860; and monthly air humidity related coefficient respectively for 0.5090 and 0.5170 ; and monthly evaporation correlation of wind was noticeably weak. 

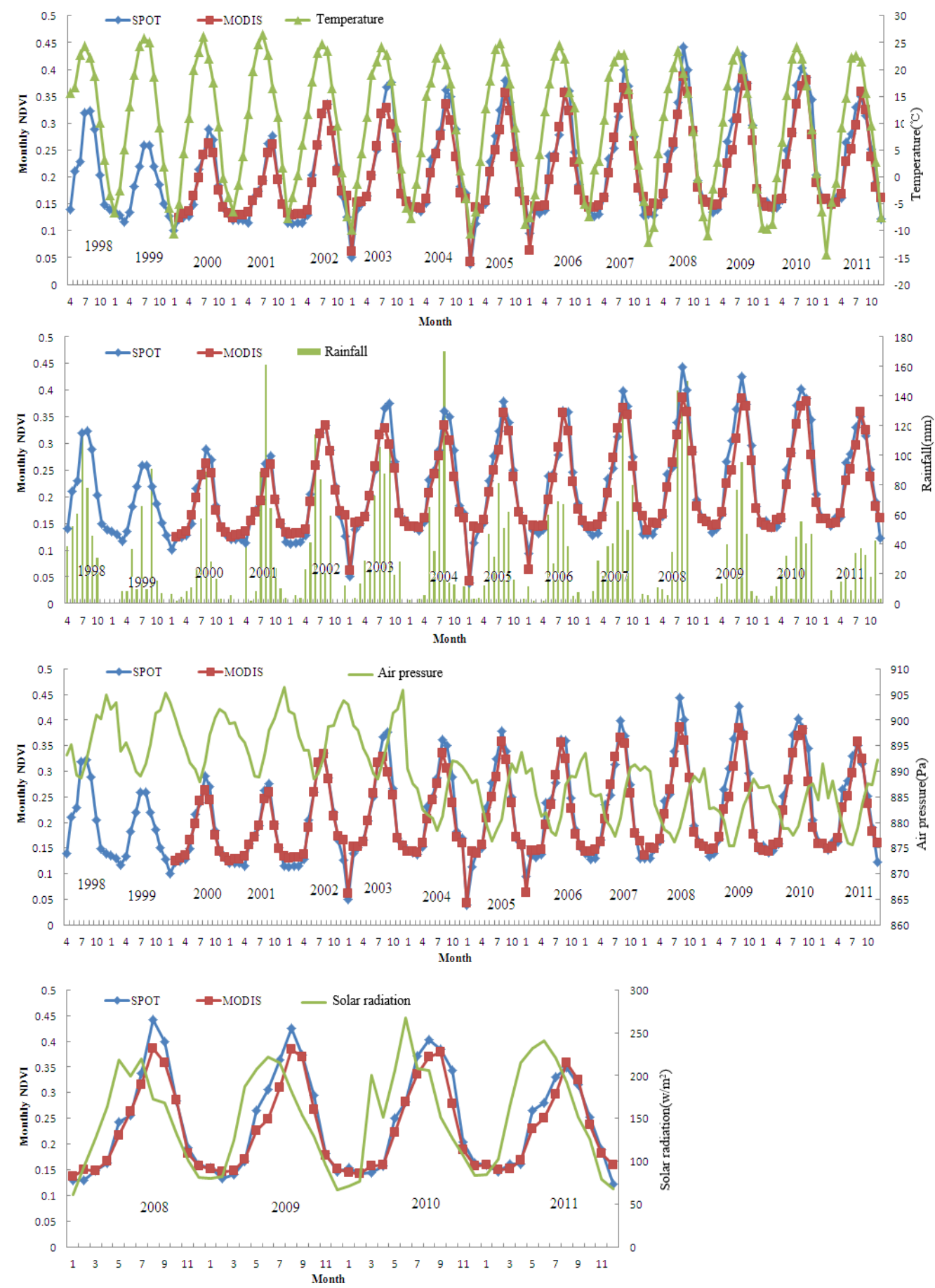

\section{Figure 5. Comparison between Monthly Maximum SPOT/MODIS NDVI and Climate Factors}

Monthly average temperatures, rainfall, solar radiation, air pressure and maximize monthly SPOT/MODIS annual and seasonal changes of NDVI have similar characteristics (Figure 5). Due to the similarity of the annual cycle, temperature, air pressure, precipitation, solar radiation and other meteorological factors on monthly mean maximum NDVI has high relevance, and there is also a correlation between meteorological factors, the correlation coefficient between the 0.6 0.9. 
Table 1. Correlation between SPOT/MODIS NDVI and Climate Factors

\begin{tabular}{|c|c|c|c|c|c|c|c|c|c|}
\hline & $\begin{array}{l}\text { MODIS } \\
\text { NDVI }\end{array}$ & $\begin{array}{l}\text { SPOT } \\
\text { NDVI }\end{array}$ & rainfall & rainfall & $\begin{array}{l}\text { air } \\
\text { pressure }\end{array}$ & $\begin{array}{c}\text { temperatur } \\
\mathrm{e}\end{array}$ & $\begin{array}{c}\text { humidit } \\
\mathrm{y}\end{array}$ & $\begin{array}{l}\text { wind } \\
\text { speed }\end{array}$ & $\begin{array}{c}\text { solar } \\
\text { radiatio } \\
n\end{array}$ \\
\hline $\begin{array}{l}\text { MODIS- } \\
\text { NDVI }\end{array}$ & 1 & $\begin{array}{c}.9810^{*} \\
*\end{array}$ & $\begin{array}{c}.6850^{*} \\
*\end{array}$ & .1790 & $\begin{array}{c}- \\
.4860 * *\end{array}$ & $.7420 * *$ & $.5170^{* * *}$ & $\begin{array}{c}.2380^{*} \\
*\end{array}$ & $.5520^{* *}$ \\
\hline $\begin{array}{l}\text { SPOT- } \\
\text { NDVI }\end{array}$ & & 1 & $\begin{array}{c}.6950^{*} \\
*\end{array}$ & $\begin{array}{c}.2270 * \\
*\end{array}$ & $.5100^{* *}$ & $.7350^{* *}$ & $.5090^{* * *}$ & $\begin{array}{c}- \\
.2390 * \\
*\end{array}$ & $.5800 * *$ \\
\hline rainfall & & & 1 & $\begin{array}{c}.2320 * \\
*\end{array}$ &.$\overline{-}$ & $.6420 * *$ & $.4900 * *$ & -.0810 & $.3760^{* *}$ \\
\hline evaporation & & & & 1 & $\begin{array}{c}- \\
.4740 * *\end{array}$ & $.7430 * *$ & $-.4310 * *$ & $\begin{array}{c}.3740 * \\
*\end{array}$ & $.8080^{* *}$ \\
\hline air pressure & & & & & 1 & $-.4790 * *$ & .0700 & $-.1880^{*}$ & $\begin{array}{c}- \\
.8600^{* *}\end{array}$ \\
\hline $\begin{array}{c}\text { temperatur } \\
\mathrm{e}\end{array}$ & & & & & & 1 & .1280 & $\begin{array}{c}.0550 \\
-\end{array}$ & $.8760^{* *}$ \\
\hline humidity & & & & & & & 1 & $\begin{array}{c}.4780^{*} \\
*\end{array}$ & -.1150 \\
\hline $\begin{array}{c}\text { wind speed } \\
\text { solar }\end{array}$ & & & & & & & & 1 & -.0810 \\
\hline $\begin{array}{l}\text { radiation } \\
\text { coal output }\end{array}$ & & & & & & & & & 1 \\
\hline
\end{tabular}

Temperature, precipitation and other meteorological factors are the main factors which controlled vegetation growth. Mass of underground mining activities had not caused mine vegetation environment of obviously deteriorated, the reasons could be: in natural factors aspects, 1998-2001 years of drought makes vegetation index obviously declined, but after 2002 , rainfall gradually recovery to perennial level, vegetation had obviously of recovery; in artificial factors including national in West big development process in the implementation returning also forest also grass, and ban Shepherd and fence captive. On the other hand, Shendong mine corporation insisted coal mining and environment governance both of approach, tons coal cost in the extraction 0.45 Yuan for ecological construction and environment improved, with mine coal production of constantly rose, for mine environment governance of funds also constantly increased, mine vegetation coverage by $3 \sim 11 \%$ had been improved to $60 \%$, and in mine mining district reclamation, and sewage processing, and windproof sand, and water protection, aspects do has many effectiveness significantly to work, an ecological, and environmental, and green mine is built.

\section{Conclusions}

Combining environment and disaster monitor with analysis by using satellite remote sensing in Shendong mining area, MODIS and SPOT vegetation index were used to analyze the spatial-temporal evolution patterns of vegetation in Shendong mining area. The spatial-temporal evolution patterns of vegetation and impacts of underground mining based on remote sensed data in Shendong mining area is evaluated. The vegetation cover is better enhanced in study area although some negative influence was generated by mining. Temperature, precipitation and other meteorological factors is the main factor controlling vegetation growth. Vegetation caused by large-scale mining activities have not been significant degradation of the environment, instead of shendong coal mining and imposed greening and ecological environment in mining area of policy, and it has played a positive role to increase vegetation coverage. It shows that the SPOT and MODIS NDVI data can be used for the monitoring and analysis on vegetation coverage in lager coalmining areas in Northwest China. 


\section{Acknowledgements}

This work was jointly supported by the National Natural Science Foundation of China (Grant No. 41401496), Scientific research program of Shaanxi Educational Committee (Grant No. 14JK1471), Doctoral scientific research foundation (Grant No. 2014QDJ060 and 2014QDJ061) and Research Development Fund (Grant No.201305 and 201306) of Xi'an University of science and Technology. The authors also thank the anonymous reviewers and the editor for their valuable comments to improve the presentation of the paper.

\section{References}

[1] L. Sun, R. Sun, and X. W. Li, "Monitoring surface soil moisture status based on remotely sensed surface temperature and vegetation index information," Agr. Forest Meteorol, vol. 41, no. 3, (2012), pp. 166167.

[2] N. R. Patel, R. Anapashsha and S. Kumar, "Assessing potential of MODIS derived temperature/vegetation condition index (TVDI) to infer soil moisture status", International Journal of Remote Sensing, vol. 30, no. 1 ,(2009), pp. 1366-1388.

[3] M. T. Schnur, H. J. Xie and X. W. Wang, "Estimating root zone soil moisture at distant sites using MODIS NDVI and EVI in a semi -arid region of southwestern USA," Ecological Informatics, vol. 5, no. 5, (2010), pp. 400-409.

[4] D. Stow, S. Daeschner and A. Hope, "Variability of the seasonally integrated normalized difference vegetat ion index across the north slope of Alaska in the 1990s," International Journal of Remote Sensing, vol. 24, no. 5, (2003), pp. 1111-1117.

[5] Y. Lu, H. Tao and H. Wu, "Dynamic drought monitoring in Guangxi using revised temperature vegetation dryness index," Wuhan University Journal of Natural Sciences, vol. 12, no. 4, (2007), pp. 663-668.

[6] I. Sandholt, K. Rasmussen and J. Andersen, "A simple interpretation of the surface temperature/vegetation index space for assessment of surface moisture status", Remote Sensing of Environment, vol. 79, no. 2, (2002), pp. 213-224.

[7] L. Telesca and R. Lasaponara, "Quantifying intra-annual persistent behaviour in SPOT-NDVI data for Mediterranean ecosystems of Southern Italy," Remote Sensing of Environment, vol. 101, no. 1, (2006), pp. $95-103$.

[8] R. Lasaponara, "On the use of principal component analysis (PCA) for evaluating inter2annual vegetation anomalies from SPOT/NDVI temporal series," Ecological Modelling, vol. 194, no. 4, (2006), pp. $429-434$.

[9] M. S. Moran, T. R. Clarke and Y. Tnoue, "Estimating crop water deficit using the relation between surface-air temperature and spectral vegetation index," Remote Sensing of Environment, vol. 49, no. 3, (1994), pp. 246-263.

[10] L. Jarlan, S. Mangiarotti and E. Mougina, "Assimilation of SPOT/NDV I data into a sahelian vegetation dynamics model," Remote Sensing of Environment, vol. 112, no. 4, (2008), pp. 1381-1394.

[11] R. R. Nemani and S. W. Running, "Estimation of regional surface resistance to evapotranspiration from NDVI and thermal IR AVHRR data," J. Appl. Meteor, vol. 8, no. 4, (1989), pp. 276-284.

[12] T. N. Carlson, R. R. Gillies and E. M. Perry, "A method to make use of thermal infrared temperature and NDVI measurements to infer surface soil water content and fractional vegetation cover," Remote Sensing Reviews, vol. 9, no.1, (1994), pp.161-173.

[13] D. Girolimetto and V. Venturini, "Water stress estimation from NDVI-Ts plot and the wet environment evapotranspiration", Adv. Remote Sens, vol. 9, no. 2, (2013), pp. 283-291.

[14] Z. G. Sun, Q. X. Wang and B. K. Matsushita, "Evaluation of the VI-Ts method for estimating the land surface moisture index and air temperature using ASTER and MODIS data in the North China Plain," Int. J. Remote Sens, vol. 32, no. 22, (2011), pp. 7257-7278.

[15] Y. Juliena, J. A. Sobrinoa, and C. Mattar, "Temporal analysis of normalized difference vegetation index (NDVI) and land surface temperature (LST) parameters to detect changes in the Iberian land cover between 1981 and 2001," Int. J. Remote Sens, vol. 32, no. 7, (2011), pp. 2057-2068.

[16] P. X. Wang, X. W. Li and J. Y. Gong, "Vegetation temperature condition index and its application for drought monitoring," in Proceedings of International Geoscience and Remote Sensing Symposium, (2001), pp. 141-143, Sydney, Australia. 


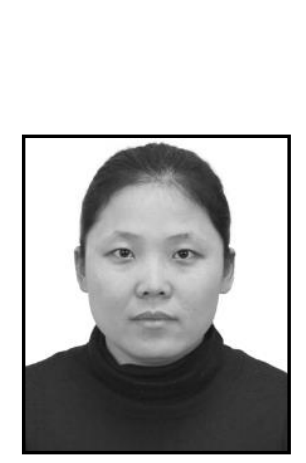

\begin{abstract}
Authors
Liu Ying, she was born in Shandong province, China in 1982. She received her B.S. degree and M.E. degree in land resources management from Northwest Agriculture \& Forestry University, Yangling, China. In 2013 she received Ph.D. degree in photogrammetry and remote sensing from China University of Mining and Technology (Beijing). Now she is a Lecturer in Xi' an University of Science and Technology, Xi'an, China. Her research interests concentrate on environmental remote sensing and image processing.
\end{abstract}

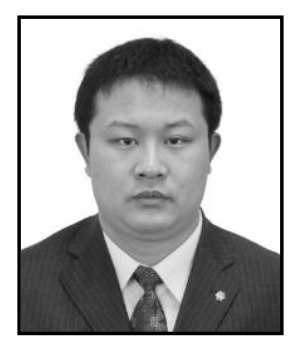

Yue Hui, he was born in Shandong province, China in 1983. He received his B.S. degree in Resources and environment and urban and rural planning and management from Liaocheng University, Liaocheng, China, in 2006. In 2009 he received M.E. degree in environment and sustainability in Monash University. In 2013 he received Ph.D. degree in environmental sciences from China University of Mining and Technology (Beijing). Now he is a Lecturer in Xi'an University of Science and Technology, Xi'an, China. His current research interests include environmental remote sensing and environmental remediation. 
International Journal of Signal Processing, Image Processing and Pattern Recognition Vol.8, No.6 (2015) 